\title{
Perfil sociodemográfico dos trabalhadores de saúde afastados durante a pandemia de
}

Covid-19 no Piauí

\author{
Sociodemographic profile of health workers away during the Covid-19 pandemic in Piauí \\ Perfil sociodemográfico de los trabajadores de la salud ausentes durante la pandemia de Covid-19
}

en Piauí

Recebido: 09/12/2021 | Revisado: 14/12/2021 | Aceito: 16/12/2021 | Publicado: 22/12/2021

\author{
Bárbara Lima Reis \\ ORCID: https://orcid.org/0000-0001-7461-1478 \\ Centro Universitário UNINOVAFAPI, Brasil \\ E-mail: barbara_lima_reis@ hotmail.com \\ Lara Beatriz Pereira França \\ ORCID: https://orcid.org/0000-0001-6974-3193 \\ Centro Universitário UNINOVAFAPI, Brasil \\ E-mail: larabeatrizfranca@hotmail.com \\ Williams Cardec da Silva \\ ORCID: https://orcid.org/0000-0002-7167-4876 \\ Centro Universitário UNINOVAFAPI, Brasil \\ E-mail: willcardec@gmail.com
}

\begin{abstract}
Resumo
A Covid-19 é uma enfermidade respiratória causada pelo novo coronavírus (SARS-CoV-2), que. A Organização Mundial de Saúde (OMS) declarou, em janeiro de 2020, que essa doença constitui uma Emergência de Saúde Pública de Importância Internacional, com mais de 5 milhões de casos confirmados e alto índice de mortalidade. Durante a pandemia, ocorreram profundas alterações de jornada de trabalho, principalmente dos profissionais de saúde, que estão na linha de frente de combate ao coronavírus e passaram a realizar horas extras, aumentaram a intensidade de trabalho, consequentemente, tiveram maior tempo de contato com vírus ocasionando assim um alto índice de infecção por parte dos trabalhadores. Essas infecções estão associadas à, pouco conhecimento sobre o vírus e suas medidas de diagnostico, transmissão e tratamento; inadequação ou falhas nas medidas de precaução e de proteção contra o surto; escassez de equipamentos de proteção individual (máscaras cirúrgicas e do tipo PFF2 e vestuário) e indivíduos infectados e assintomáticos que mantiveram contato com colaboradores de saúde. A importância desse trabalho é avaliar o impacto do coronavírus na saúde dos trabalhadores de saúde nessa pandemia, analisar e estratificar a quantidade de profissionais que foram afastados da sua atividade laboral por estar contaminado por Covid-19. Desse modo, todos os serviços de saúde precisam garantir mecanismos e medidas de proteção e de promoção à saúde, uma vez que a atuação desses servidores da saúde é essencial para o enfrentamento da pandemia.
\end{abstract}

Palavras-chave: Trabalhadores de saúde; Covid-19; Afastamento.

\begin{abstract}
Covid -19 is a respiratory disease caused by the new coronavirus (SARS-CoV-2), which. The World Health Organization (WHO) declared, in January 2020, that this disease constitutes a Public Health Emergency of International Importance, with more than 5 million confirmed cases and a high mortality rate. During the pandemic, there were profound changes in working hours, especially for health professionals, who are at the forefront of fighting the coronavirus and started to work overtime, increased the work intensity, consequently, had a longer time of contact with viruses. Thus causing a high rate of infection by workers. These infections are associated with, little knowledge about the virus and its diagnostic, transmission and treatment measures; inadequacy or failures in the precautionary and protection measures against the outbreak; shortage of personal protective equipment (surgical and PFF2 masks and clothing) and infected and asymptomatic individuals who maintained contact with health workers. The importance of this work is to assess the impact of the coronavirus on the health of health workers in this pandemic, to analyze and stratify the number of professionals who have been removed from their work activity because it is contaminated by Covid-19. Thus, all health services need guarantee mechanisms and measures for the protection and promotion of health, since the work of these health workers is essential to face the pandemic.
\end{abstract}

Keywords: Health workers; Covid-19; Removal. 


\begin{abstract}
Resumen
Covid-19 es una enfermedad respiratoria causada por el nuevo coronavirus (SARS-CoV-2), que. La Organización Mundial de la Salud (OMS) declaró, en enero de 2020, que esta enfermedad constituye una Emergencia de Salud Pública de Importancia Internacional, con más de 5 millones de casos confirmados y una alta tasa de mortalidad. Durante la pandemia, se produjeron cambios profundos en la jornada laboral, especialmente para los profesionales de la salud, que están a la vanguardia de la lucha contra el coronavirus y comenzaron a trabajar horas extras, aumentaron la intensidad del trabajo, en consecuencia, tuvieron un mayor tiempo de contacto con los virus. Una alta tasa de infección por parte de los trabajadores. Estas infecciones están asociadas con poco conocimiento sobre el virus y sus medidas de diagnóstico, transmisión y tratamiento; inadecuación o fallas en las medidas de precaución y protección contra el brote; escasez de equipo de protección personal (máscaras y ropa quirúrgica y PFF2) e individuos infectados y asintomáticos que mantuvieron contacto con los trabajadores de la salud. La importancia de este trabajo es evaluar el impacto del coronavirus en la salud de los trabajadores de la salud en esta pandemia, para analizar y estratificar el número de profesionales que han sido retirados de su actividad laboral por estar contaminados por Covid-19. Así, Todos los servicios de salud necesitan mecanismos de garantía y medidas para la protección y promoción de la salud, ya que el trabajo de estos trabajadores de la salud es fundamental para enfrentar la pandemia.
\end{abstract}

Palabras clave: Trabajadores de la salud; Covid-19; Licencia.

\title{
1. Introdução
}

No dia 31 de dezembro de 2019 a Organização Mundial de Saúde (OMS) foi informada, na China, sobre casos de pneumonia de etiologia desconhecida na cidade de Wuhan, Província de Hubei. O agente causal da doença foi, posteriormente, denominado SARS-CoV-2. No final de janeiro de 2020 havia 7.734 casos confirmados na China e 90 registrados em outros países. A taxa de mortalidade calculada era de 2,2\%. A situação foi declarada emergência de Saúde Pública de Interesse internacional (Almeida, 2020).

Em 30 de janeiro de 2020, a OMS declarou a epidemia da Covid-19 uma Emergência de Saúde Pública de Importância Internacional, o mais alto nível de alerta da Organização, conforme previsto no Regulamento Sanitário Internacional. Posteriormente, em 11 de março de 2020, a Covid-19 foi declarada como pandemia pela OMS (Sohrabi, et al.,2020). No Brasil, o segundo óbito por coronavírus registrado foi o de uma empregada doméstica no Rio de Janeiro, cuja doença foi contraída no exercício do trabalho (Lemos, 2020).

O enfrentamento da pandemia do novo coronavírus faz parte das funções essenciais da Saúde Pública por meio de ações voltadas para a população ou para grupos com maior risco de contaminação, como os profissionais de saúde (Filho, et al.,2020).

No entanto, outras atividades de trabalho podem ter um papel relevante na disseminação do vírus e, portanto, a análise de como se processam é determinante para a prevenção do adoecimento. A pouca visibilidade desse aspecto implica sua pouca valorização nas políticas públicas. O campo do trabalho como um todo deve ser considerado na estratégia de enfrentamento da Covid-19 (Filho, et al., 2020).

Além disso, a pandemia de Covid-19 trouxe para o cenário mundial a necessidade de pensar o trabalho de cuidado realizado na saúde, pois são os(as) médicos(as), enfermeiros(as) e técnicos(as), fisioterapeutas, psicólogos(as) e assistentes sociais que fazem esse trabalho e, portanto, estão à frente dos programas de prevenção da doença e até dos atendimentos dos casos mais graves. De acordo com o Conselho Federal de Enfermagem (Cofen), no dia 1 de dezembro de 2020, os infectados eram 43.788, e os óbitos de profissionais 460. Destes, 63,9\% eram de mulheres. Por meio desse dado numérico, já podemos constatar as dificuldades e as violências relacionadas às condições de trabalho enfrentadas por esses (as) profissionais no contexto brasileiro (Vedovato, et al., 2020).

No caso específico dos profissionais de saúde, estima-se, com base nos dados disponíveis que, na China, mais de 3.000 profissionais tenham se infectado com o coronavírus, dos quais 23 morreram (Xiang, et al., 2020). Na Itália 4.884 casos de Covid-19 ocorreram entre profissionais de saúde com 24 óbitos de médicos (Anelli, et al., 2020). As infecções estão associadas à inadequação ou falhas nas medidas de precaução e de proteção contra o surto, escassez de equipamentos de proteção individual (máscaras cirúrgicas e do tipo PFF2 e vestuário), presença de aglomerações, indivíduos infectados e assintomáticos que 
mantiveram contato com médicos, enfermeiros (as) e demais trabalhadores (as) da saúde, dentre outros fatores (Xiang, et al.,2020).

Na mesma linha, o Conselho Federal de Medicina (CFM), em mensagem expedida aos médicos brasileiros no dia 30 de março de 2020, alertou sobre a obrigatoriedade do fornecimento de EPIs aos profissionais que estão na linha de frente de combate à pandemia de Covid-19, bem como criou, através de um link especial, um fórum para denúncias de descumprimento dessa obrigatoriedade nas condições de trabalho.

A legislação trabalhista brasileira, via Norma Regulamentadora de Segurança e Saúde no Trabalho em Serviços de Saúde (NR32), indica a obrigatoriedade de o empregador prover ao trabalhador EPI em quantidade suficiente, descartáveis ou não, que sejam necessários para o desenvolvimento seguro das tarefas de trabalho. Além do fornecimento, deve-se assegurar a capacitação de forma contínua e a garantia de proteção ao trabalhador sempre que houver mudança das condições de exposição a agentes biológico (Brasil, 2005).

Apesar de serem fundamentais para a garantia da vida de populações inteiras, ações de atenção à saúde e segurança desses/as trabalhadores/as nem sempre são incorporadas às medidas de enfrentamento do problema. Essa dimensão precisa ser problematizada, ao mesmo tempo que medidas específicas e urgentes devem ser priorizadas, especialmente nesse contexto de reorganização da vida social, dos serviços, dos ambientes e dos processos de trabalho em saúde como resposta à pandemia de Covid-19 (Helioterio, et al.,2020).

Diante disso, em função da importância e da relevância do atual tema, esse estudo tem como objetivo quantificar e estratificar os profissionais de saúde contaminados por Covid-19 no estado do Piauí e analisar a condição laboral que se encontram como forma de exposição, baseando-se no cenário atual, frente a uma pandemia.

\section{Metodologia}

O presente projeto de pesquisa contará com dois acadêmicos do curso de medicina, conjuntamente com orientador docente do Centro Universitário UNINOVAFAPI. Tal estudo consistirá na análise quantitativa e descritiva de profissionais de saúde que foram afastados da sua atividade laboral durante a pandemia Covid-19 na cidade de Teresina-Piauí no período de 1 de maio a 31 de dezembro de 2020 .

Conjuntamente com análise de dados publicados na literatura médica e em banco de dados Scielo, PubMed e nas informações divulgadas na Organização Mundial de Saúde (OMS), Ministério da Saúde (MS), Normas regulamentadoras (NR) e Medidas Provisórias trabalhistas para enfrentamento do estado de calamidade pública e de emergência de saúde de impetencia internacional decorrente de coronavírus (Covid-19).

A autorização do acesso aos dados será disponibilizada pela Secretaria de Saúde do Estado do Piauí. A coleta será realizada por meio da observação e análise direta dos dados disponibilizados pela Secretaria de Saúde do Estado do Piauí.

\subsection{Critérios de inclusão}

Trabalhadores de saúde que foram afastados da sua atividade laboral durante a pandemia Covid-19 por positivarem para coronavírus; por diferentes tipos de teste, de qualquer sexo, tipo profissional da saúde e regiões de trabalho, e no período de 1 de maio a 31 de dezembro de 2020.

\subsection{Critérios de exclusão}

Trabalhadores que não foram afastados da sua atividade laboral durante a pandemia Covid-19, não contaminados por Covid-19, no período de 1 de maio a 31 de dezembro de 2020. 


\subsection{Coleta de dados}

A coleta será realizada por meio da observação e análise direta dos dados disponibilizados pela Secretaria de Saúde do Estado do Piauí. A amostra para o estudo constará de 6766 trabalhadores da saúde selecionados, aleatoriamente, entre os que foram afastados da sua atividade laboral por positivarem para Covid-19 durante a pandemia no Estado do Piauí no período de 1 de maio a 31 de dezembro de 2020. Esse número foi calculado através da fórmula aplicável a populações infinitas:

$\mathrm{n}=(\mathrm{z} 2 \cdot 0,25 \cdot) /(\mathrm{E} 2)=(1,962 \cdot 0,25 /(0,052)$, na qual, $\mathrm{z}$ é o valor crítico e $\mathrm{E}$ a margem de, considerando o grau de confiança de $95 \%(z=1,96)$, margem de erro $E=5 \%$ e população infinita.

A coleta de dados será realizada nos meses de fevereiro a março de 2021, pelos próprios pesquisadores, após a autorização da Secretaria de Saúde do Estado do Piauí.

O instrumento utilizado será uma ficha de coleta de dados (APÊNDICE A) contendo as variáveis do estudo abrangendo: sexo; cargo; tipo de teste para Covid- 19 e município de residência.

\subsection{Análise dados}

Os dados coletados serão submetidos a uma análise estatística descritiva através das frequências absolutas e relativas para descrever e listar dados caracterizando o os perfis sociodemográficos dos trabalhadores de saúde afastados por Covid-19 no Estado do Piauí. Para estabelecer relações entre variáveis será aplicado o teste qui-quadrado com grau de confiança de $95 \%$. O processamento será feito por meio da planilha Excel e do Programa SPSS. Os resultados serão apresentados em forma de tabelas e gráficos.

\subsection{Aspectos éticos}

O projeto de pesquisa será submetido à comissão de ética e pesquisa do Centro Universitário UNINOVAFAPI. De acordo com a resolução 466/2012 (BRASIL, 2012), todo protocolo de pesquisa será submetido à revisão ética, para tanto o mesmo será lançado na Plataforma Brasil, para análise e monitoramento do sistema CEP/CONEP.

A análise dos prontuários será feita de forma anônima, sem identificação nominal das pessoas em um estudo observacional quantitativo após a Solicitação da Dispensa de Termo de Consentimento Livre e Esclarecido (TCLE) e Termo de Assentimento Livre e Esclarecido (TALE) estiver aprovada, baseado na Resolução 466/12 do Conselho Nacional de Saúde (Brasil, 2012), que trata dos procedimentos éticos da pesquisa que envolve seres humanos. Ressalta-se que serão utilizadas apenas informações dos dados obtidos no EPISUS de modo que os resultados da pesquisa não permitirão a identificação individual dos participantes e não trará riscos, prejuízos ou qualquer ônus ao bem-estar deles, pois trata-se de um estudo não intervencionista.

Esta pesquisa respeitará o sigilo e confidencialidade dos dados assim como consta no Termo de Compromisso de Utilização de Dados (TCUD) e permitirá um conhecimento maior acerca de uma temática importante em um cenário no qual a literatura em questão ainda se encontra em formação.

\subsection{Riscos}

Essa pesquisa não apresenta riscos do tipo biológico, químico ou físico para os participantes, pois serão utilizados apenas os dados pertinentes à pesquisa, a partir da coleta do material presente em uma ficha: trabalhadores da saúde que foram afastados da sua atividade laboral por positivarem para Covid-19 durante a pandemia no Estado do Piauí. Não possui risco de extravasamento de informações pessoais, pois não há nenhum dado pessoal possível de identificação. 


\subsection{Benefícios}

Identificar o perfil sociodemográfico de afastamentos laborais dos profissionais de saúde e referir os benefícios diretos para a comunidade por meio da divulgação dos resultados após sua conclusão. A pesquisa é relevante pois trata sobre a descrição do cenário atual na epidemiologia brasileira descrevendo o perfil sociodemográfico de trabalhadores de saúde afastados das suas atividades laborais devido o diagnóstico positivo para Covid-19.

\section{Resultados e Discussão}

Para análise e discussão sobre o afastamento de trabalhadores de saúde durante a pandemia do Covid-19 no ano de 2020, foram desenvolvidas tabelas que cruzaram os dados entre os tipos de testes para confirmação do Covid-19, tipo de profissional de saúde, o sexo do profissional de saúde afastados por Covid-19, e as regiões do Piauí que esses profissionais atuavam.

Em abril de 2020, o Ministério da Saúde (MS) emitiu documento sobre distribuição e oferta de testes rápidos para a Covid-19 para estados e municípios, assim como critérios estabelecidos para contemplar seu uso, tendo como prioridade profissionais da saúde, profissionais da segurança pública e população considerada grupo de risco. Para a distribuição equitativa dos testes para estados e municípios, foi realizada uma estimativa do quantitativo profissional de trabalhadores(as) da saúde em toda rede assistencial a partir de dados disponíveis no Departamento de Informática do Sistema Único de Saúde (Datasus). Apesar do documento do MS elucidar o planejamento para a oferta dos testes para Covid-19 para profissionais de saúde, muitas reportagens relataram dificuldade no acesso e, consequentemente, sua não realização. Em caso de realização do teste com diagnóstico positivo para a Covid-19, o(a) trabalhador(a) da saúde é afastado(a) por 14 dias após início dos sintomas; o mesmo procedimento acontece em caso de resultado positivo para o contato domiciliar do(a) profissional de saúde. Entretanto, sem a realização do teste, somente a presença dos sintomas pode indicar outro possível adoecimento, o que pode levar ao afastamento com número de dias reduzido (Vedovato, et al., 2020).

Atualmente, o diagnóstico laboratorial para Covid-19 inclui as técnicas de: testes moleculares de amplificação de ácido nucleico de SARS-CoV-2 por PCR em tempo real (RT-PCR); testes imunológicos (teste rápido ou sorologia clássica para detecção de anticorpos); e confirmação por sequenciamento parcial ou total do genoma viral, quando necessário (Brasil, 2020).

$\mathrm{Na}$ presente pesquisa, os tipos de testes realizados para confirmação do diagnostico para Covid-19 (Tabela 1) em profissionais da saúde no Piauí, apresentou maior frequência com TESTE RÁPIDO - ANTICORPO correspondendo a 52,2\%, seguido por RT- PCR com 25,2\%, o terceiro maior foi TESTE RÁPIDO- ANTÍGENO com 20,8\%, posteriormente IMUNOENSAIO POR ELETROQUIMIOLUMINESCÊNCIA-ECLIA apresentando 1,1\%, QUIMIOLUMINESCÊNCIACLIA COM $0,8 \%$.

Tabela 1 - Tipo de testes realizados para confirmação de Covid-19 no período de 1 maio a 31 de dezembro de 2020.

\begin{tabular}{clcc}
\hline & & Frequência & $\%$ \\
\hline \multirow{2}{*}{$\begin{array}{c}\text { Tipo de } \\
\text { Teste }\end{array}$} & Imunoensaio por Eletroquimioluminescência - ECLIA & 79 & $1,10 \%$ \\
& Quimioluminescência - CLIA & 51 & $0,80 \%$ \\
& RT-PCR & 1702 & $25,20 \%$ \\
& Teste Rápido - Anticorpo & 3529 & $52,20 \%$ \\
& Teste Rápido - Antígeno & 1405 & $20,80 \%$ \\
\hline
\end{tabular}

Fonte: Autores. 
Conforme Hankivsky, ressalta-se ainda que a força de trabalho em saúde não é homogênea, porquanto apresenta diferença de gênero, raça e classe social, estruturantes do acesso aos diversos níveis e cursos de formação profissional, bem como das oportunidades de inserção no mercado de trabalho reproduzindo-se no cotidiano das relações de trabalho no âmbito dos serviços de saúde.

Segundo o Fundo de População das Nações Unidas (UFNPA), a pandemia de Covid-19 impõe, na área da saúde, a necessidade de ações simultâneas de atendimento emergencial, planejamento e pesquisa e, ainda, um olhar atento às questões de gênero em todas essas ações. Dentre os efeitos imediatos dessa pandemia, o Fundo de População das Nações Unidas (UNFPA) destaca a acentuação das desigualdades de gênero e a piora da qualidade de vida das mulheres. Além disso, mostra a predominância das mulheres na força de trabalho da saúde e, por conseguinte, na linha de frente do combate à Covid-19.

Isso pode ser observado de acordo com a tabela 2 , onde os profissionais de saúde do sexo feminino afastados durante a pandemia por Covid-19 foram responsáveis por $73,1 \%$ dos contaminados e $26,9 \%$ eram do sexo masculino.

Tabela 2 - Identificação de gênero dos profissionais de saúde afastados por Covid-19 no período de 1 maio a 31 de dezembro de 2020.

\begin{tabular}{ccccc}
\hline & & Freq. & $\%$ \\
\hline \multirow{2}{*}{ Sexo } & Feminino & 4943 & $73,10 \%$ \\
& Masculino & 1823 & $26,90 \%$ \\
\hline
\end{tabular}

Fonte: Autores.

No presente contexto de calamidade pública, uma análise superficial poderia levar à conclusão, equivocada, de que as diferenças de gênero entre os componentes das equipes de saúde voltadas ao enfrentamento da pandemia não seriam relevantes. Entretanto, relações de gênero não comportam simplificações, como destaca a análise de Barata (2009):

As relações de gênero atravessam todas as dimensões da vida social, possuem dinâmica própria independente de outros processos sociais e são marcadas pelo antagonismo na relação de dominação das mulheres pelos homens. A idealização do papel do trabalho remunerado, como elemento de fortalecimento da identidade e da liberdade feminina, desaparece face à constatação da pouca ou nenhuma qualificação da maioria dos postos de trabalho ocupados pelas mulheres, dos salários inferiores para as mesmas funções e da dupla jornada, representada pelo trabalho doméstico ou pelas tarefas de cuidado destinado a membros da família das quais invariavelmente são as mulheres que se ocupam (Barata, 2009, p. 77).

Em muitos relatos de trabalhadores(as) e de representantes de sindicatos de diferentes categorias foi destacado o número de trabalhadores(as) afastados(as). Em alguns lugares do país representavam a metade dos casos do município. Ressaltamos que a área de saúde vem passando por precarização do trabalho, com a escassa contratação de profissionais e restrição de recursos materiais, o que traz dificuldades àqueles(as) que estão na linha de frente dos atendimentos contra a Covid-19.

Conforme a Tabela 3, o município mais afetado é a capital Teresina com 3506 casos de colaboradores de saúde confirmados, perfazendo 51,8\% do total. Dentre os 207 municípios do Piauí que tiveram profissionais de saúde afetados, 39 (84,6\%) possuíram os maiores registros de trabalhadores de saúde afastados por Covid-19. A capital do Estado, Teresina, é o município com a maior quantidade de casos confirmados. A razão desse achado é decorrente do fato do município ser o de maior densidade populacional, e, portanto, tem o maior contingente de pessoas circulando, além disso, a cidade configura-se como o epicentro da epidemia no Estado. Além disso, Teresina iniciou os testes rápidos antes de outras regiões, o que aumentou o número de notificações. Essa ampla testagem de trabalhadores suspeitos é essencial para reduzir o aumento de casos por Covid-19, já que detecta precocemente o indivíduo contaminado. 
Research, Society and Development, v. 10, n. 17, e141101724597, 2021

(CC BY 4.0) | ISSN 2525-3409 | DOI: http://dx.doi.org/10.33448/rsd-v10i17.24597

Tabela 3 - Cidades piauiense onde os profissionais de saúde afastados por Covid-19 no período de 1 maio a 31 de dezembro de 2020 .

\begin{tabular}{|c|c|c|c|}
\hline & Piauí & Frequência & $\%$ \\
\hline \multirow{39}{*}{ Região } & Água Branca & 21 & $0,3 \%$ \\
\hline & Altos & 39 & $0,60 \%$ \\
\hline & Alegrete do Piauí & 15 & $0,20 \%$ \\
\hline & Barras & 55 & $0,80 \%$ \\
\hline & Bom Jesus & 71 & $1,00 \%$ \\
\hline & Buriti dos Lopes & 32 & $0,50 \%$ \\
\hline & Campo Maior & 147 & $2,20 \%$ \\
\hline & Castelo do Piauí & 19 & $0,30 \%$ \\
\hline & Corrente & 46 & $0,70 \%$ \\
\hline & Curimatá & 24 & $0,40 \%$ \\
\hline & Elesbão Veloso & 26 & $0,40 \%$ \\
\hline & Esperantina & 49 & $0,70 \%$ \\
\hline & Floriano & 114 & $1,70 \%$ \\
\hline & Inhuma & 27 & $0,40 \%$ \\
\hline & Ipiranga do Piauí & 49 & $0,70 \%$ \\
\hline & Jaicós & 17 & $0,30 \%$ \\
\hline & José de freitas & 42 & $0,60 \%$ \\
\hline & Luís Correia & 17 & $0,30 \%$ \\
\hline & Luzilândia & 22 & $0,30 \%$ \\
\hline & Marcolândia & 16 & $0,20 \%$ \\
\hline & Miguel Alves & 18 & $0,30 \%$ \\
\hline & Monsenhor Gil & 15 & $0,20 \%$ \\
\hline & Oeiras & 259 & $3,80 \%$ \\
\hline & Parnaíba & 304 & $4,50 \%$ \\
\hline & Paulistana & 45 & $0,70 \%$ \\
\hline & Pedro II & 27 & $0,40 \%$ \\
\hline & Picos & 210 & $3,10 \%$ \\
\hline & Piripiri & 101 & $1,50 \%$ \\
\hline & Regeneração & 21 & $0,30 \%$ \\
\hline & Ribeiro Gonçalves & 54 & $0,80 \%$ \\
\hline & Santa Cruz do Piauí & 21 & $0,30 \%$ \\
\hline & São João do Piauí & 43 & $0,60 \%$ \\
\hline & São Pedro do Piauí & 23 & $0,30 \%$ \\
\hline & São Raimundo Nonato & 137 & $2,00 \%$ \\
\hline & Simplício Mendes & 32 & $0,50 \%$ \\
\hline & Teresina & 3506 & $51,80 \%$ \\
\hline & União & 48 & $0,70 \%$ \\
\hline & Uruçui & 58 & $0,90 \%$ \\
\hline & Valença do Piaui & 87 & $1,30 \%$ \\
\hline
\end{tabular}

Fonte: Autores.

Conforme os dados fornecidos pela Secretária de Saúde do Estado do Piauí, 6766 profissionais da área de saúde tiveram o diagnóstico positivo para Covid-19 mais da metade deles (3565 - 52,8\%) eram enfermeiros ou técnicos e auxiliares em enfermagem, seguido deles são os médicos $11,1 \%$, agente comunitário de saúde $5,8 \%$, fisioterapeuta $4,3 \%$ e outros $26 \%$ aponta 
o boletim epidemiológico da Secretária Estadual do Estado do Piauí durante o período 1 maio a 31 de dezembro de 2020 , como consta a Tabela 4.

Tabela 4 - Os profissionais de saúde afastados por Covid-19 no período de 1 de maio a 31 de dezembro.

\begin{tabular}{|c|c|c|c|}
\hline & & Frequência & $\%$ \\
\hline \multirow{6}{*}{$\begin{array}{l}\text { Tipos de } \\
\text { profissionais da } \\
\text { saúde }\end{array}$} & Médico & 750 & $11,10 \%$ \\
\hline & Enfermeiro & 1335 & $19,80 \%$ \\
\hline & Técnicos/ auxiliares em enfermagem & 2230 & $33 \%$ \\
\hline & Fisioterapeuta & 290 & $4,30 \%$ \\
\hline & Agente comunitário de saúde & 391 & $5,80 \%$ \\
\hline & Outros & 1770 & $26 \%$ \\
\hline
\end{tabular}

Fonte: Autores.

Brasil responde por um terço do total de mortes pela Covid-19 entre os profissionais da categoria, um dado alarmante tendo em vista que sem eles, salvar vidas nos hospitais todos os dias se torna uma tarefa hercúlea. O dado global mais recente sobre letalidade da Covid-19 entre profissionais da área foi divulgado em novembro pelo Conselho Internacional da categoria, e dava conta de 1.500 mortos em 44 países — a cifra já deve ter sido superada. "O fato de que o número de enfermeiros e enfermeiras mortos na pandemia seja similar aos que faleceram na I Guerra Mundial é chocante”, afirmou Howard Catton, chefeexecutivo da entidade durante a divulgação do relatório de óbitos, fazendo um paralelo entre a atual crise sanitária e um dos conflitos mais violentos da história humana (Alessi, 2021).

As mortes e afastamentos pela doença entre profissionais de Saúde fomentaram o mercado de vagas na área, com um perigoso efeito colateral para os profissionais. "Muita gente nova foi contratada, existe uma demanda enorme por gente da enfermagem", afirma Souza. Os novatos, porém, não contam com a experiência dos veteranos que já estão na linha de frente desde março, o que pode trazer riscos adicionais para eles, desacostumados com todos os procedimentos e medidas necessárias de autocuidado.

Verificaram em um hospital regional da China que tratou mais de 35 casos confirmados e mais de 260 casos suspeitos de Covid-19, que mesmo com treinamento intenso, não é incomum que os enfermeiros descuidem da exposição enquanto cuidam de pacientes, especialmente quando se sentem estressados ou exaustos, situação que se verifica especialmente após longas jornadas de trabalho, o que pode aumentar o risco de contaminação. De fato, a maior parte do trabalho dos enfermeiros envolve contato direto com pacientes, portanto esses profissionais têm alta vulnerabilidade ao Covid-19, sendo necessário estabelecer protocolos hospitalares específicos para reduzir o risco de infecção desses nas interações com pacientes com Covid-19 (Huang, et al., 2020).

De acordo com Souza, os profissionais dessa área, como enfermeiros, fisioterapeutas, médicos e técnicos de enfermagem, por trabalharem em contato direto com pacientes e seus fluidos, estão entre os mais vulneráveis à infecção da Covid-19. Isso ocasiona estresse e pressão psicológica por causa da possibilidade de se infectar e espalhar o vírus para seus próprios familiares, colegas de trabalho e até mesmo pacientes. Somado a isso, longas jornadas de trabalho, falta de equipamentos de proteção individual (EPI) e infraestrutura de atendimento precária podem causar sentimentos de solidão e desesperança, além de estados emocionais como irritabilidade, cansaço mental, físico e desespero. Outro fator agravante é que, com o afastamento de colegas de trabalho por conta da infecção pelo coronavírus (ou por causa de outros motivos), há sobrecarga no trabalho por diminuição da equipe, que aumenta ainda mais o estresse crônico. 
Desse modo, é por meio das condições de trabalho que são analisadas as inserções no mercado de trabalho (contratações, estabilidade na carreira, bem como riscos à saúde e à segurança no cotidiano profissional). E, com a precariedade das condições de trabalho, o adoecimento profissional é uma realidade em diversas áreas, cabendo à gestão do trabalho proporcionar meios dignos e seguros a todos(as) os(as) trabalhadores(as) para a garantia da saúde, particularmente no contexto pandêmico, em que o risco de contaminação pelo novo coronavírus é um dos desafios para os profissionais de saúde e da gestão do trabalho (Vedovato, et al., 2020).

\section{Conclusão}

Os resultados aqui apresentados baseiam-se em materiais de dados da Secretária do Estado de Saúde disponíveis de 1 maio a 31 de dezembro de 2020 demonstram a situação atual em que se percebe a tensão entre a gestão de trabalho saudável e classe trabalhadora. Portanto, o que precisa ser garantido é que a saúde desses trabalhadores seja garantida.

A pandemia de Covid-19 mudou a forma de pensar sobretudo naqueles profissionais que são linha de frente em cuidado a saúde da população. Analisar as inserções dos profissionais de saúde no mercado de trabalho, principalmente, em relação a saúde do trabalhador que envolve os riscos à saúde e a segurança do trabalho. A precariedade do trabalho, que inclui o alto risco de infecção e proteção inadequada contra contaminação, estresse, falta de contato com a família foram fatores primordiais que contribuíram para o afastamento desses do campo de trabalho. Logo, cabe a gestão de trabalho conceder meios seguros, dignos para esses trabalhadores, assim, como aumentar a quantidade de profissionais de saúde contratados para o enfrentamento dessa pandemia.

Não há dúvidas que a pandemia de Covid-19 necessitou de mudanças repentinas na saúde do trabalhador, uma vez que paralela a disseminação do vírus foi necessária alterações e, normas, resoluções, leis para abranger a prevenção a saúde dos profissionais na linha de frente. Esses profissionais que se dedicam ao cuidado da saúde da população, a assistência médica a essas pessoas passa a ser de responsabilidade ética, moral e política da sociedade, do país e das instituições responsáveis pela saúde. Os profissionais, além do reconhecimento social, não só recebem aplausos, mas também obtêm políticas públicas que proporcionam melhores condições de trabalho e se mantêm efetivas mesmo após a pandemia do coronavírus.

As atividades de enfermagem são vitais para a saúde e o bem-estar de toda a sociedade. Experiência e conhecimentos específicos de diferentes campos de ação podem fornecer prevenção, promoção e tratamento saudáveis. No entanto, o trabalho em saúde não escapou das contradições da sociedade capitalista, que explora trabalhadores de determinados setores e põe em risco sua vida. Portanto, a situação de pandemia mostra que as pessoas na vanguarda da promoção da saúde precisam urgentemente de cuidados e proteção.

Desse modo, é tão importante conteúdos exploratórios cada vez mais proveitosos sobre todas as áreas que intervém na dinâmica medicina e sobre a esfera de trabalho que os profissionais da saúde se encontram em tempos de pandemia por Covid19 e como esses elementos influenciam no processo de direito e bem-estar consequente.

\section{Referências}

Anelli, et al., (2020). Italian doctors call for protecting healthcare workers and boosting community surveillance during covid-19 outbreak. BMJ, 368 : m1254, 1-2, https://doi.org/10.1136/bmj.m1254.

Alessi. (2021). Brasil responde por um terço das mortes globas entre profissionais de enfermagem por covid-19, https://brasil.elpais.com/brasil/2021-0108/brasil-responde-por-um-terco-das-mortes-globais-entre-profissionais-de-enfermagem-por-covid-19.html.

Almeida. (2020). Proteção da saúde dos trabalhadores da saúde em tempos de COVID-19 e respostas à pandemia. Rev. Bras. Saúde Ocup. 45 e17, 2. https://doi.org/10.1590/SciELOPreprints.140.

Barata, R. B. (2009). Relações de gênero e saúde: desigualdade ou discriminação? In: Como e por que as desigualdades sociais fazem mal à saúde.

Editora FIOCRUZ. 
Research, Society and Development, v. 10, n. 17, e141101724597, 2021

(CC BY 4.0) | ISSN 2525-3409 | DOI: http://dx.doi.org/10.33448/rsd-v10i17.24597

Brasil, Ministério do Trabalho e Emprego. Gabinete do Ministro. Portaria nº 485, de 11 de novembro de 2005.

Brasil, Ministério da Saúde, (2020). Coronavírus covid-19. Diretrizes para Diagnóstico e Tratamento da Covid-19, v1. Ministério da Saúde.

Filho, et al., (2020). A saúde do trabalhador e o enfrentamento da COVID-19. Rev. Bras. Saúde Ocup. 45 e14, 1. https://doi.org/10.1590/2317-6369ED0000120.

Hankivsky O., \& Kapilashramim A. (2020).Beyond sex and gender analysis: an intersectional view of the COVID-19 pandemic outbreak and response. Gender and Women's Health Unit, Centre for Health Equity, Melbourne School of Population and Health Equity University of Melbourne. https://mspgh.unimelb.edu.au/news-and-events/beyond-sex-and-gender-analysis-an-intersectional-view-of-the-covid-19-pandemic-outbreak-and-response.

Helioterio, Margarete C. et al. (2020). Covid-19: por que a proteção da saúde dos trabalhadores e trabalhadoras da saúde é prioritária no combate à pandemia? Trabalho, Educação e Saúde, 18(3), e00289121. https://doi.org/10.1590/1981-7746-sol00289.

Huang L., Lin G., Tang L., Yu L., Zhou Z. (2020). Special attention to nurses' protection during the COVID-19 epidemic. Critical Care. 24:120, 1-3. https://doi.org/10.1186/s13054-020-2841-7

Lemos, (2020). Ministério Público do Trabalho analisa morte de doméstica no RJ após patroa ter coronavírus; https://www.bbc.com/portuguese/brasil-51982465.

Souza, (2020). Impactos na saúde mental dos profissionais da saúde durante a pandemia da COVID-19, https://www.informasus.ufscar.br/impactos-na-saudemental-dos-profissionais-da-saude-durante-a-pandemia-da-covid-19/

Soharbi C, et al. (2020). Corrigendum to World Health Organization Declares Global Emergency: A Review of the 2019 Novel Coronavirus (COVID-19). International Journal of Surgery. 76, 71. https://doi.org/10.1016/j.ijsu.2020.02.034.

Vedovato, et al., (2020). Trabalhadores(as) da saúde e a COVID-19: condições de trabalho à deriva?. Rev. Bras. Saúde Ocup. 46 e1, 2. https://doi.org/10.1590/2317-6369000028520.

Xiang, Y. T., Yang, Y., Li, W. et al. (2020). Timely mental health care for the 2019 novel coronavirus outbreak is urgently needed. The Lancet Psychiatry, 7(3), 228- 229. https://doi.org/10.1016/S2215-0366(20)30046-8. 